\title{
Cerebral microembolization during off-pump coronary artery bypass surgery with the Symmetry aortic connector device
}

Mona Skjelland, MD, ${ }^{a}$ Jacob Bergsland, MD, ${ }^{b}$ Runar Lundblad, MD, PhD, ${ }^{\mathrm{c}}$ Per Snorre Lingaas, $\mathrm{MD},{ }^{\mathrm{c}}$

Kjell Arne Rein, MD, PhD, ${ }^{c}$ Steinar Halvorsen, MD, Jan L. Svennevig, MD, PhD, ${ }^{\mathrm{c}}$ Erik Fosse, MD, PhD,

Rainer Brucher, PhD, and David Russell, MD, PhD, FRCPE ${ }^{\mathrm{a}}$

From the Department of Neurology, ${ }^{\mathrm{a}}$ The Interventional Center, ${ }^{\mathrm{b}}$ and the Department of Thoracic and Cardiovascular Surgery, ${ }^{\mathrm{c}}$ Rikshospitalet University Hospital, Oslo, Norway.

Supported by a grant from The Norwegian Foundation for Health and Rehabilitation.

Received for publication April 4, 2005; revisions received Aug 12, 2005; accepted for publication Aug 16, 2005.

Address for reprints: Mona Skjelland, MD, Department of Neurology, Rikshospitalet University Hospital, Oslo, Norway (E-mail: mona.skjelland@rikshospitalet.no).

J Thorac Cardiovasc Surg 2005;130:1581-5

0022-5223/\$30.00

Copyright (C) 2005 by The American Association for Thoracic Surgery

doi:10.1016/j.jtcvs.2005.08.015
Objective: The use of aortic connector systems for proximal vein grafts in off-pump coronary artery bypass grafting might minimize aortic manipulation by eliminating the need for partial aortic clamping. The objective of this study was to asses whether use of a Symmetry connector (St Jude Medical, Inc, St Paul, Minn) reduced intraoperative cerebral embolization.

Methods: Thirty-two consecutive patients underwent off-pump coronary artery bypass grafting. Sixteen patients received at least one mechanical proximal vein graft anastomosis with a Symmetry aortic connector system. Sixteen patients representing the control group underwent operations with standard suturing techniques using partial aortic clamping. During surgical intervention, all patients were monitored continuously with multifrequency transcranial Doppler scanning, which detected and differentiated cerebral emboli.

Results: There were significantly more cerebral emboli in the Symmetry group (median, 36) compared with the control group (median, $11 ; P=.027$ ). This was due to a higher number of gaseous emboli in the Symmetry group than in the control group (median, 27 vs $8 ; P=.014$ ), whereas there was no significant difference regarding the number of solid emboli (median, 7 vs $3 ; P=.139$ ).

Conclusion: Use of a Symmetry connector system during proximal vein graft anastomosis increased the number of emboli to the brain compared with a standard technique in coronary bypass surgery without cardiopulmonary bypass.

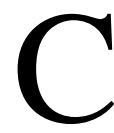
oronary artery bypass grafting $(\mathrm{CABG})$ has adverse effects on the brain. One of the main causes is cerebral emboli, which are most frequent during cannulation and clamping of the aorta. ${ }^{1-4}$ Studies have shown a positive relationship between the atheromatous burden of the ascending aorta and cerebral embolization, as well as the incidence of postoperative stroke. ${ }^{5-7}$ Off-pump coronary bypass grafting $(\mathrm{OPCAB})$ avoids insertion of an aortic cannula, which in several studies has shown less cerebral microembolization compared with $\mathrm{CABG}{ }^{8-10}$ Although it has been assumed that aortic connector systems that exclude clamping of the aorta will reduce cerebral embolization compared with OPCAB, this has not been confirmed in previous studies. The aim of this study was to assess whether OPCAB performed with a connector system reduces the number of intraoperative cerebral emboli measured using multifrequency transcranial Doppler scanning.

\section{Patients and Methods}

The study included 32 patients, 4 women and 28 men, who were aged between 48 and 85 years (mean, 65.6 years). This was a pilot study before a planned larger randomized trial. However, when the angiograms 3 months after the operation showed higher occlusion rates 


\section{Abbreviations and Acronyms \\ $\mathrm{CABG}=$ coronary artery bypass grafting \\ $\mathrm{dEBR}=$ difference embolus blood ratio $(2.5 \mathrm{MHz}-$ $2.0 \mathrm{MHz})$ \\ $\mathrm{OPCAB}=$ off-pump coronary artery bypass grafting}

for the connected vein grafts than expected, ${ }^{11}$ the pilot phase was extended to only 16 connector patients, and 16 patients were included as control subjects. The groups were similar with regard to preoperative comorbidity, age, sex, and number of veins grafts (Table 1). In the connector group 5 patients had 1, 10 patients had 2 , and 1 patient had 3 proximal vein grafts. In the control group 5 patients had 1 and 11 patients had 2 proximal vein grafts. Patients scheduled for OPCAB requiring at least 1 saphenous vein graft were included consecutively. In the first 16 patients, the proximal vein graft was attached to the aorta with a St Jude Symmetry aortic connector system (St Jude Medical, Inc, Minneapolis, Minn). In the other 16 patients, partial aortic clamping and standard suturing techniques for vascular anastomosis were used. Clinical neurologic examination was carried out the day before and the day after surgical intervention and repeated 3 months later. The study was approved by the regional ethics committee, and all patients provided written informed consent before admission to the study.

\section{Operative Technique and Procedures}

Surgical intervention was elective and carried out without a heartlung machine in all patients. Standardized anesthesia and sternotomy were performed in all patients, as previously described at our hospital. ${ }^{11}$ Heparin was administered after the internal thoracic artery was harvested. Activated coagulation time was maintained at greater than 250 seconds. The ascending aorta was palpated by the surgeon before partial clamping and perforation by the connector device in an attempt to avoid the most atherosclerotic areas of the artery. All of the surgeons who performed the procedure had extensive experience with $\mathrm{CABG}$ and had undergone companyapproved training with the Symmetry device. Perforation of the aorta in the Symmetry group was completed without the use of an aortic clamp. The anastomosis system has been described in previous studies. ${ }^{12-15}$ In the control group standard suturing techniques and partial aortic clamping were used. In both groups the proximal vein anastomoses were attached before the distal anastomoses. All patients had a revascularization to the left anterior descending coronary artery from the internal thoracic artery. Coronary angiography was carried out on the operating table immediately postoperatively, and all vein grafts were patent. All patients received aspirin preoperatively and postoperatively.

\section{Doppler Monitoring}

During surgical intervention, both middle cerebral arteries were monitored for microemboli by using multifrequency transcranial Doppler scanning (EmboDop; DWL, Singen, Germany). Cerebral microemboli were continuously identified and differentiated automatically, and their time of occurrence was simultaneously registered. The criteria for detection and differentiation of cerebral microemboli with multifrequency Doppler scanning were based on
TABLE 1. Patient characteristics

\begin{tabular}{lcc}
\hline & Symmetry group & Control group \\
\hline $\mathrm{N}$ & 16 & 16 \\
Mean age, y (range) & $66.4(43-85)$ & 64.9 (53-77) \\
Male sex, n & 14 & 14 \\
Previous heart infarct, n & 3 & 3 \\
Previous stroke, n & 1 & 0 \\
Distal anastomoses, n (mean) & 2.8 & 2.7 \\
Proximal anastomoses, n (mean) & 1.8 & 1.7 \\
\hline
\end{tabular}

those described previously ${ }^{16,17}$ but refined as follows. The detection level for microemboli was a $7 \mathrm{~dB}$ or greater power increase above background level (embolus blood ratio [dEBR]) that lasted $4 \mathrm{~ms}$ or longer simultaneously in both $2.0-$ and $2.5-\mathrm{MHz}$ frequency channels, and the lower dEBR detection limit for solid emboli was as follows: $\mathrm{y}=-0.1 \mathrm{x}-0.12 \mathrm{~dB}$, where $\mathrm{y}=\mathrm{dEBR}$ and $\mathrm{x}=2.0$ MHz EBR. ${ }^{18}$ The insonation and reference gate depths were 45 and $55 \mathrm{~mm}$, and the sample volume was $12 \mathrm{~mm}$, filter setting was $200 \mathrm{~Hz}$, power was $188 \mathrm{~mW}$, and scale was 120/96. Transcranial Doppler scanning was performed continuously from incision of the pericardium until the start of chest wall closing.

\section{Statistical Methods}

The Mann-Whitney test was used to correlate the quantity of microembolization between the median values in the 2 groups. All calculations were carried out with the SPSS software program (version 11.0; SPSS Inc, Chicago, Ill).

\section{Results}

There was a significantly higher median total number of emboli in the Symmetry group (36; range, 3-115) compared with the control group ( 11 ; range, $4-48 ; P=.027)$. None of the operations were completed without embolic signals, but $44 \%$ of the patients in the control group and $19 \%$ in the Symmetry group had 10 or fewer emboli. There was a significantly higher median number of gaseous emboli (27; range, 2-100) in the Symmetry group compared with the control group ( 8 ; range, $1-44 ; P=.014)$. For the number of solid emboli (Figure 1), there was no statistically significant difference, but there was a trend toward a higher median number in the Symmetry group (7; range, 0-21) compared with the control group (3; range, $1-9 ; P=.139$; Table 2$)$. Thirty-nine emboli (range, 6-115) were recorded in the 11

TABLE 2. Numbers and type of cerebral microemboli in the 2 groups

\begin{tabular}{lccc}
\hline & $\begin{array}{c}\text { Symmetry group } \\
(\mathbf{n}=\mathbf{1 6})\end{array}$ & $\begin{array}{c}\text { Control group } \\
(\mathbf{n}=\mathbf{1 6})\end{array}$ & $\boldsymbol{P}$ value \\
\hline Total emboli & $36(3-115)$ & $11(4-48)$ & .027 \\
Gaseous emboli & $27(2-100)$ & $8(1-44)$ & .014 \\
Solid emboli & $7(0-21)$ & $3(1-9)$ & .139 \\
\hline
\end{tabular}

Data are presented as medians, with ranges in parentheses. 


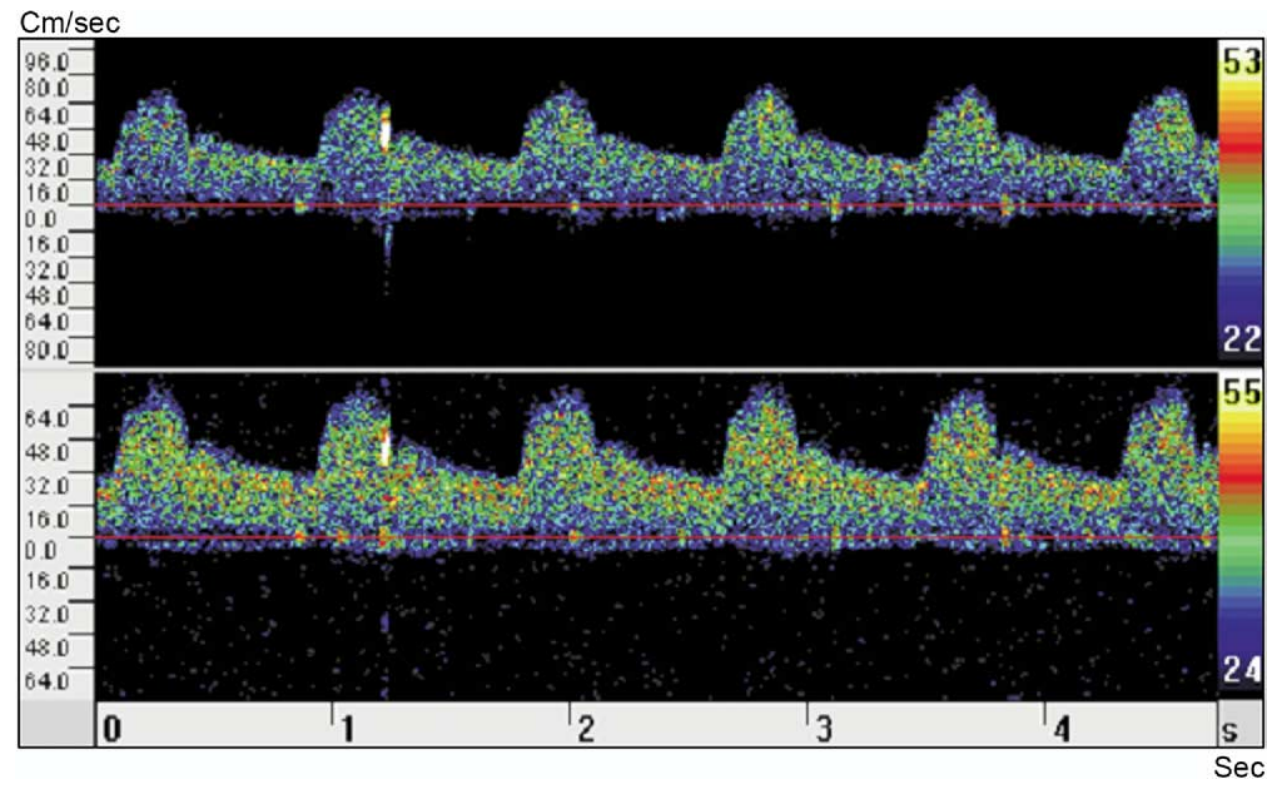

Figure 1. A solid microemboli (white) entering the middle cerebral artery during OPCAB with the Symmetry connector. The reflection of ultrasound was greater at insonation of $2.5 \mathrm{MHz}$ (bottom) compared with that at 2.0 MHz (top).

patients in the Symmetry group who had 2 or 3 proximal vein grafts, whereas there were 21 emboli (range, 3-47) in patients with 1 graft. This difference was not significant $(P$ $=.5$ ), which might have been due to the small numbers of patients. The 2 patients with the highest number of emboli (both solid and gaseous) were in the Symmetry group. The patient with the highest number of gaseous and the second highest number of solid emboli (100 gaseous and 16 solid) experienced peroperative cardiac arrest and postoperative tamponade. This patient had cognitive impairment with reduced memory and impaired orientation for time and situation on clinical neurologic evaluation 3 months post-

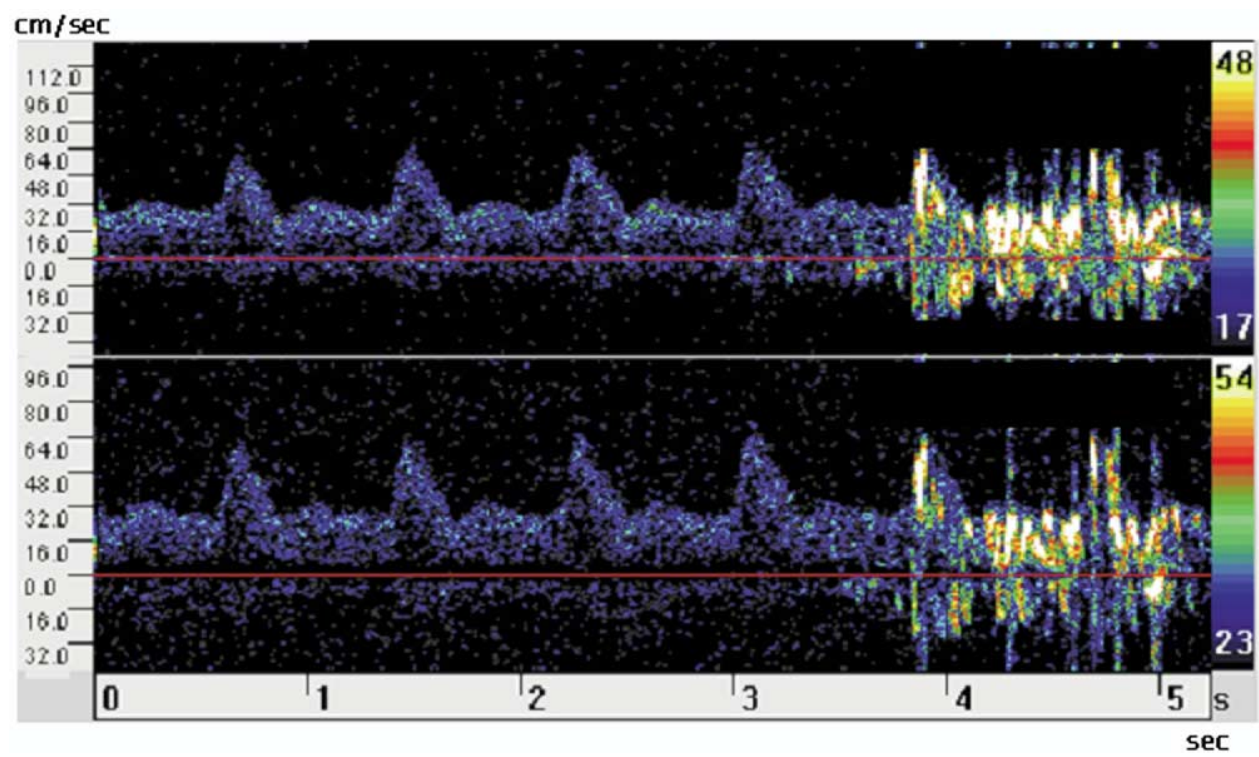

Figure 2. A burst of multiple gaseous microemboli in the middle cerebral artery during a proximal vein graft anastomosis with the Symmetry connector system. 
operatively. In the rest of the patient population, there were no new neurologic deficits after the operation. There was no mortality in either group.

\section{Discussion}

The use of a Symmetry anastomotic device makes aortic clamping unnecessary during $\mathrm{OPCAB}$ operations and was considered a step toward reduced aorta manipulation and risk of cerebral embolization. This study suggests, however, that OPCAB with a Symmetry connector device might lead to a higher number of cerebral emboli compared with the standard technique. The appearance of microemboli in the Symmetry group, both solid and gaseous, was mainly limited to the first 5 to 10 seconds after attaching the connector device and the vein to the aorta. During this procedure, solid atherosclerotic material might be fragmented when the connector penetrates the aorta. The increased number of gas bubbles might be due to a Venturi effect, which occurs when the introducer is pushed against the aortic wall, thereby causing a shift in the aortic diameter. ${ }^{19}$ This might cause air to be sucked into the bloodstream during connector attachment. Another possibility is that air in the connector system is pressed into the aorta during the attachment procedure. In the control group emboli were mainly related to partial clamping of the aorta, especially removal of the clamp, which is in accordance with previous studies. ${ }^{4,8}$

This is the first study in which cerebral embolus detection and differentiation has been carried out during OPCAB with the Symmetry connector system. The median number of gaseous emboli was 3 times larger than the median number of solid emboli. This difference might be even greater because there probably was an underestimation of the number of individual emboli when several emboli entered the sample volume at the same time (Figure 2). This is often the case during CABG. It is at present impossible for Doppler instrumentation to count each single embolus when they occur. The overall majority of emboli identified in these situations were, however, gaseous.

Scarborough and coworkers ${ }^{20}$ have previously demonstrated significantly reduced cerebral microembolization in OPCAB using the Symmetry connector system compared with routine on-pump CABG. It is likely that their observation was due to avoidance of the heart-lung machine rather than use of the Symmetry connector. Both our group and others have previously demonstrated a large reduction in cerebral microembolization in off-pump surgery compared with on-pump surgery..$^{8-10}$

The amount of atheromatous debris released because of manipulation of the ascending aorta during cardiac surgery has been demonstrated by intra-aortic filter capture. $^{21}$ Martens and associates ${ }^{22}$ found no significant dif- ference in captured debris between operations with the Symmetry anastomotic device and conventional handsewn anastomoses, which is in accordance with the results of this study.

One study with 250 patients who underwent OPCAB did not demonstrate any difference in the incidence of postoperative stroke between patients treated with Symmetry aortic connectors and partial aortic clamping for proximal anastomosis. ${ }^{23}$ Another study, however, showed a significant reduction in postoperative neurologic events in patients aged 70 years and older undergoing OPCAB with the aortic connector compared with partial occlusion clamping on the aorta. ${ }^{24}$ There is therefore a possibility that minimizing aortic manipulation might be particularly beneficial in selected groups, such as high-risk older patients with severe atherosclerosis. ${ }^{25-27}$

The major limitation of our study was the small number of patients. This was, however, due to cancellation of a larger study that was stopped because of an unacceptable incidence of restenosis and occlusions in the Symmetry group. ${ }^{11}$ The St Jude Symmetry aortic connector device that we used in this study is no longer commercially available, but it was used worldwide after US Food and Drug Administration approval in 2001. The results of this study are, however, probably relevant for the connector systems that are at present in clinical use.

Microembolus differentiation allows us to gain information not only about the composition but also about the potential size of an embolus. ${ }^{16-18}$ The size of emboli that can be detected with this method is 3 to $40 \mu \mathrm{m}$ for gaseous emboli and 80 to $400 \mu \mathrm{m}$ for solid emboli. In our study the majority of the gaseous emboli caused a Doppler power increase of between 10 and $30 \mathrm{~dB}$, which correlates to emboli with a diameter from 4 to $40 \mu \mathrm{m}$. The Doppler power increase for solid microemboli was usually between 8 and $20 \mathrm{~dB}$, which theoretically corresponds to diameters from 80 to $120 \mu \mathrm{m}$. It is therefore more likely that solid microemboli, which might consist of atherosclerotic material, platelet aggregates, or soft fat-containing particles, cause more harm to the brain because it would seem unlikely that they could pass through the brain's microvasculature $(7-10 \mu \mathrm{m})$. However, although gaseous microemboli might pass through this microvasculature or be dissolved there with little or no immediate interruption of flow, their passage might cause damage to the endothelium and activation of leukocytes, which can cause secondary ischemia.

In conclusion, this study has shown that use of a Symmetry aortic connector device did not reduce but in fact increased the number of emboli that entered the brain during OPCAB. It is therefore unlikely that these devices will play a major role in reducing the incidence of stroke and cognitive impairment in the general OPCAB population. 


\section{References}

1. Roach GW, Kanchuger M, Mangano CM, Newman M, Nussmeier N, Wolman R, et al. Adverse cerebral outcomes after coronary bypass surgery. Multicenter Study of Perioperative Ischemia Research Group and the Ischemia Research and Education Foundation Investigators. N Engl J Med. 1996;335:1857-63.

2. Taylor KM. Brain damage during cardiopulmonary bypass. Ann Thorac Surg. 1998;65(suppl):S20-6.

3. Selnes OA, Goldsborough MA, Borowicz LM, McKhann GM. Neurobehavioural sequelae of cardiopulmonary bypass. Lancet. 1999;353: 1601-6.

4. Braekken SK, Russell D, Brucher R, Abdelnoor M, Svennevig JL. Cerebral microembolic signals during cardiopulmonary bypass surgery: frequency, time of occurrence, and association with patient and surgical characteristics. Stroke. 1997;28:1988-92.

5. Mackensen GB, Ti LK, Phillips-Bute BG, Mathew JP, Newman MF, Grocott HP, et al. Cerebral embolization during cardiac surgery: impact of aortic atheroma burden. Br J Anaesth. 2003;91:656-61.

6. van der Linden J, Hadjinikolaou L, Bergman P, Lindblom D. Postoperative stroke in cardiac surgery is related to the location and extent of atherosclerotic disease in the ascending aorta. $\mathrm{J} \mathrm{Am} \mathrm{Coll} \mathrm{Cardiol}$. 2001;38:131-5.

7. Barbut D, Lo YW, Hartman GS, Yao FS, Trifiletti RR, Hager DN, et al. Aortic atheroma is related to outcome but not numbers of emboli during coronary bypass. Ann Thorac Surg. 1997;64:454-9.

8. Lund C, Hol PK, Lundblad R, Fosse E, Sundet K, Tennoe B, et al. Comparison of cerebral embolization during off-pump and on-pump coronary artery bypass surgery. Ann Thorac Surg. 2003;76:765-70.

9. Bowles BJ, Lee JD, Dang CR, Taoka SN, Johnson EW, Lau EM, et al. Coronary artery bypass performed without the use of cardiopulmonary bypass is associated with reduced cerebral microemboli and improved clinical results. Chest. 2001;119:25-30.

10. Watters MP, Cohen AM, Monk CR, Angelini GD, Ryder IG. Reduced cerebral embolic signals in beating heart coronary surgery detected by transcranial Doppler ultrasound. Br J Anaesth. 2000;84:629-31.

11. Bergsland J, Hol PK, Lingas PS, Lundblad R, Rein KA, Andersen R, et al. Intraoperative and intermediate-term angiographic results of coronary artery bypass surgery with Symmetry proximal anastomotic device. J Thorac Cardiovasc Surg. 2004;128:718-23.

12. Carrel TP, Eckstein FS, Englberger L, Windecker S, Meier B. Pitfalls and key lessons with the symmetry proximal anastomotic device in coronary artery bypass surgery. Ann Thorac Surg. 2003;75:1434-6.

13. Katariya K, Yassin S, Tehrani HY, Lombardi P, Masroor S, Salerno TA. Initial experience with sutureless proximal anastomoses performed with a mechanical connector leading to clampless off-pump coronary artery bypass surgery. Ann Thorac Surg. 2004;77:563-7.
14. Eckstein FS, Bonilla LF, Englberger L, Immer FF, Berg TA, Schmidli $\mathrm{J}$, et al. The St Jude Medical symmetry aortic connector system for proximal vein graft anastomoses in coronary artery bypass grafting. J Thorac Cardiovasc Surg. 2002;123:777-82.

15. Mack MJ, Emery RW, Ley LR, Cole PA, Leonard A, Edgerton JR, et al. Initial experience with proximal anastomoses performed with mechanical connector. Ann Thorac Surg. 2003;75:1866-70.

16. Brucher R, Russell D. Automatic online embolus detection and artefact rejection with the first multifrequency transcranial Doppler. Stroke. 2002;33:1969-74.

17. Russell D, Brucher R. Online automatic discrimination between solid and gaseous cerebral microemboli with the first multifrequency transcranial Doppler. Stroke. 2002;33:1975-80.

18. Russell D, Brucher R. Embolus detection and differentiation using multifrequency transcranial Doppler. Stroke. 2005;36:706.

19. Ritter MA, Ringelstein EB. The venture effect and cerebrovascular ultrasound. Cerebrovasc Dis. 2002;14:98-104.

20. Scarborough JE, White W, Derilus FE, Mathew JP, Newman MF, Landolfo KP. Combined use of off-pump techniques and a sutureless proximal aortic anastomotic device reduces cerebral microemboli generation during coronary artery bypass grafting. $J$ Thorac Cardiovasc Surg. 2003;126:1561-7.

21. Bergman P, Hadjinikolaou L, van der LJ. Aortic atheroma is related to number of particulates captured by intra-aortic filtration in CABG. Eur $J$ Cardiothorac Surg. 2002;22:539-44.

22. Martens S, Dietrich M, Herzog C, Doss M, Schneider G, Moritz A, et al. Automatic connector devices for proximal anastomoses do not decrease embolic debris compared with conventional anastomoses in CABG. Eur J Cardiothorac Surg. 2004;25:993-1000.

23. Patel NC, Patel NU, Patel M, Sahani S, Patel D, Subramanian VA. Does use of proximal aortic connectors reduce incidence of postoperative neurological deficit during off pump coronary surgery? Heart Surg Forum. 2003;6(suppl 1):34.

24. Katariya K, Lombardi P, Tehrani H, Yassin S, Masroor S, Bolooki H, et al. Neurological outcome in patients age 70 years and older undergoing OPCAB with use of symmetry device. Heart Surg Forum. 2003;6(suppl 1):34.

25. Lev-Ran O, Loberman D, Matsa M, Pevni D, Nesher N, Mohr R, et al. Reduced strokes in the elderly: the benefits of untouched aorta offpump coronary surgery. Ann Thorac Surg. 2004;77:102-7.

26. Bonatti J, Nagele G, Hangler H, Danzmayr M, Mueller L, Rieger M, et al. Extraanatomical coronary artery bypass grafts on the beating heart for management of the severely atherosclerotic ascending aorta. Heart Surg Forum. 2002;5(suppl 4):272-81.

27. Bergsland J, Hasnan S, Lewin AN, Bhayana J, Lajos TZ, Salerno TA. Coronary artery bypass grafting without cardiopulmonary bypass-an attractive alternative in high risk patients. Eur J Cardiothorac Surg. 1997;11:876-80. 